\title{
Effect of cytokinin and cultivar on shoot formation of Gerbera jamesonii in vitro*
}

\author{
R. L. M. Pierik, H. H. M. Steegmans, J. A. M. Verhaegh and A. N. Wouters
}

Department of Horticulture, Agricultural University, P.O. Box 30, 6700 AA Wageningen, Netherlands

Accepted: 16 July 1982

Key-words: gerbera, shoot formation, in vitro, cytokinin

\section{Summary}

The results of clonal propagation in vitro of Gerbera jamesonii using either capitulum explants or subcultured shoots depended on the choice of the cultivar and on the cytokinin level in the medium. With capitulum explants shoot formation of some cultivars was very low and almost independent of the BA (benzyl adenine) level in the medium; in other cultivars the reaction strongly depended on the BA level $(5,10$ or $20 \mathrm{mg} / \mathrm{l})$.

Axillary branching of subcultured shoots depended on choice of the cultivar and on the kinetin concentration $(1,5$ or $10 \mathrm{mg} / 1)$ in the medium. However, the kinetin concentration for the best shoots (the highest leaf weight per shoot, no leaf deformations, no callus formation) was not always the same as the one inducing the highest number of axillary shoots.

\section{Introduction}

Previous investigations (Pierik \& Segers, 1973) with midrib explants of gerbera showed that vegetative propagation through the adventitious bud technique was not successful. Similar observations were made by Murashige et al. (1974) who worked with callus cultures of gerbera; although the callus could be subcultured indefinitely, organ regeneration occurred inconsistently, and in small numbers. However, Hedtrich (1979) regenerated adventitious buds from in vitro cultivated leaves of the gerbera cv. Vulkan on a medium with BA and $\mathrm{GA}_{3}$.

In horticultural practice only two methods for the in vitro propagation of gerbera are applied: shoot formation from excised capitulum explants (Pierik et al., 1973, 1975), and rapid clonal propagation through the isolation of shoot tips and further multiplication by axillary branching (Murashige et al., 1974). The advantages of the capitulum method are that the sterile isolation in vitro is easier

* Publication 488, Department of Horticulture, Agricultural University, Wageningen, Netherlands. 
than with shoot tips, and that it is also non-destructive: only inflorescences are used and no shoots are lost from the plant. In addition it should be stressed that the capitulum system has never been developed as a mass multiplication method. For mass propagation of gerberas only the axillary branching method ( $\mathrm{Mu}-$ rashige et al., 1974) proved to be suitable, notwithstanding the difficulty to isolate the shoot tips sterile on the medium. Shoots obtained by the capitulum method can easily be used as sterile starting material for axillary branching experiments.

The main objection against the capitulum method is that the percentage of explants with sprout formation is low or sometimes even zero. The axillary branching method has its drawbacks because less axillary shoots are obtained than described and expected, and because axillary branching often remains too strong after rooted plants had been planted in soil.

To solve the problems presented by both methods the influence of the cytokinin concentration was re-examined. The capitulum method (Pierik et al., 1975) yielded best results with $10 \mathrm{mg} / 1 \mathrm{BA}$, whereas axillary branching (Murashige et al., 1974) was optimal at $10 \mathrm{mg} / 1$ kinetin. Another factor, i.e. the cultivar, was also studied. The reason to do this was that both methods were optimalized for only one cultivar.

This paper gives the results obtained with both methods using several cultivars and various cytokinin levels.

\section{Materials and methods}

\section{Capitulum explant method}

Fully developed inflorescences with 2-3 whorls of flowering disk florets of several Gerbera jamesonii cultivars were collected from December to the end of April. After removal of disk and ligulate ray flowers intact capitula were sterilized for a few seconds in $70 \%$ ethanol, 30 minutes in $1 \% \mathrm{NaOCl}$ with Tween 20 and subsequently washed in sterilized tap water. For further details (cutting of explants, inoculation, composition of the basic culture medium, growth conditions, etc.) the reader is referred to Pierik et al. (1975). The influence of the cytokinin concentration was examined by comparing 15 cultivars om media with 5 , 10 and $20 \mathrm{mg} / 1 \mathrm{BA}$. The number of capitulum explants per cultivar and per treatment was initially 24 , but it often decreased to 18-20 due to contamination. At the end of the total culture period of 12 weeks $\left(4\right.$ weeks at $25^{\circ} \mathrm{C}$ in darkness +8 weeks at $25^{\circ} \mathrm{C}$ in continuous fluorescent light, Philips TL $40 \mathrm{~W} / 57,10 \mathrm{~W} \mathrm{~m}^{-2}$ ) the percentages of shoot-forming explants and the mean numbers of shoots per explant were determined.

\section{Axillary branching method}

Shoots formed on capitulum explants were used as the starting material. They were first multiplied 4 times according to the method and on the medium described by Murashige et al. (1974); the hormone level was $10 \mathrm{mg} / \mathrm{l} \mathrm{kinetin}$ and $0.5 \mathrm{mg} / 1$ IAA. The influence of the kinetin concentration on axillary branching 
$(1,5$ and $10 \mathrm{mg} / \mathrm{l})$ was examined just after the fourth multiplication cycle. At least 24 shoots per cultivar and per treatment were used; each test tube contained a shoot with 3-4 visible leaves attached to a small quantity of basal stem tissue. Test tubes were placed at $25^{\circ} \mathrm{C}$ in continiuous fluorescent light (Philips TL $40 \mathrm{~W} / 57,10 \mathrm{~W} \mathrm{~m}^{-2}$ ). Multiplication of shoots was determined after 7 weeks.

\section{Results}

\section{Capitulum explants}

In a preliminary experiment capitulum explants of 28 cultivars were isolated on media with $10 \mathrm{mg} / 1 \mathrm{BA}$; this concentration was chosen because it appeared to be the optimum for shoot formation in the gerbera cultivar 'Wageningen Rood' (Pierik et al., 1975). It appeared that the percentage of shoot-forming explants was strongly determined by the cultivar. Three cultivars did not react; shoot formation of 9 cultivars was $0-20 \%$; for 5 cultivars it was $20-40 \%$; for 5 cultivars it was $40-60 \%$; for 3 cultivars it was $60-80 \%$ and for 3 cultivars it was $80-100 \%$. The mean number of shoots per explant (calculated over all uninfected explants) strongly decreased when the percentage of shoot formation decreased.

In a subsequent experiment the influence of the BA concentration was examined with a restricted number of cultivars. The results are shown in Table 1 . The cultivars can rougly be divided into 3 groups. The first (B 54, Helios, Marleen, Nr. 20, Schlösser) is characterized by a very low percentage of shoot formation and a very small number of shoots per explant. This group hardly reacts to the BA concentration in the medium. The second group (Clara, Geel Moor, Wage-

Table 1. The influence of the BA concentration on shoot formation of excised capitulum explants of various Gerbera cultivars; $\% \mathrm{~S}=$ percentage of explants forming at least one shoot; $\mathrm{S} / \mathrm{E}=$ mean number of shoots per explant.

\begin{tabular}{|c|c|c|c|c|c|c|}
\hline \multirow[t]{2}{*}{ Cultivar } & \multicolumn{2}{|c|}{$5 \mathrm{mg} / 1 \mathrm{BA}$} & \multicolumn{2}{|c|}{$10 \mathrm{mg} / \mathrm{lBA}$} & \multicolumn{2}{|c|}{$20 \mathrm{mg} / \mathrm{lBA}$} \\
\hline & $\% \mathrm{~S}$ & $\mathrm{~S} / \mathrm{E}$ & $\% \mathrm{~S}$ & $\mathrm{~S} / \mathrm{E}$ & $\% \mathrm{~S}$ & $\mathrm{~S} / \mathrm{E}$ \\
\hline Agnes & 9 & 0.1 & 11 & 0.1 & 30 & 0.8 \\
\hline B 54 & 11 & 0.1 & 13 & 0.1 & 0 & 0.0 \\
\hline Clara & 100 & 7.8 & 100 & 11.3 & 86 & 5.1 \\
\hline Claudia & 33 & 0.5 & 58 & 1.7 & 41 & 1.4 \\
\hline Clementine & 33 & 0.5 & 0 & 0.0 & 0 & 0.0 \\
\hline Geel Moor & 55 & 2.7 & 70 & 4.0 & 60 & 4.4 \\
\hline Helios & 0 & 0.0 & 8 & 0.6 & 0 & 0.0 \\
\hline Jacqueline & 21 & 0.2 & 53 & 2.0 & 18 & 0.8 \\
\hline Marleen & 10 & 0.1 & 0 & 0.0 & 0 & 0.0 \\
\hline Nr. 20 & 0 & 0.0 & 0 & 0.0 & 20 & 0.2 \\
\hline Oranje Nassau & 36 & 0.4 & 75 & 2.2 & 46 & 1.1 \\
\hline Petra & 0 & 0.0 & 20 & 0.5 & 80 & 1.2 \\
\hline Ronald & 40 & 0.8 & 36 & 0.5 & 18 & 0.1 \\
\hline Schlösser & 0 & 0.0 & 10 & 0.1 & 0 & 0.0 \\
\hline Wageningen Rood & 60 & 2.1 & 100 & 4.2 & 80 & 3.2 \\
\hline
\end{tabular}


Table 2. The influence of the kinetin concentration on axillary branching of 10 Gerbera cultivars. $\mathrm{S} / \mathrm{E}=$ mean number of shoots per explant; $\mathrm{N}$, no leaf deformation; $\mathrm{S}$, some leaf deformation; $\mathrm{M}$, much leaf deformation; E, extreme leaf deformation; C, extreme callus formation; *, kinetin concentration for each cultivar at which the highest leaf weight per shoot (the best shoot quality) is obtained.

\begin{tabular}{|c|c|c|c|c|c|c|}
\hline \multirow[t]{2}{*}{ Cultivar } & \multicolumn{2}{|c|}{$1 \mathrm{mg} / 1$ kinetin } & \multicolumn{2}{|c|}{$5 \mathrm{mg} / 1$ kinetin } & \multicolumn{2}{|c|}{$10 \mathrm{mg} / \mathrm{l}$ kinetin } \\
\hline & $\mathrm{S} / \mathrm{E}$ & & $\mathrm{S} / \mathrm{E}$ & & $\mathrm{S} / \mathrm{E}$ & \\
\hline Beatrix & 5.6 & $\mathrm{~N}$ & $8.4^{*}$ & $\mathrm{~N}$ & 9.0 & $\mathrm{~N}$ \\
\hline Clementine & 2.2 & $\mathbf{N}$ & $5.5^{*}$ & $\mathbf{S}$ & 3.2 & $S$ \\
\hline Marleen & 2.5 & $\mathrm{~N}$ & 5.4 & $S$ & $9.5^{*}$ & $S$ \\
\hline Nr. 20 & 1.9 & $\mathbf{N}$ & $8.1^{*}$ & $\mathrm{~N}$ & 10.9 & $S$ \\
\hline Olga & 3.9 & $\mathbf{N}$ & $9.7^{*}$ & $\mathbf{S}$ & 13.3 & $\mathbf{S}$ \\
\hline Pari & $11.2^{*}$ & $\mathrm{~N}$ & 13.5 & $\mathrm{M}, \mathrm{C}$ & 10.2 & $\mathrm{E}, \mathrm{C}$ \\
\hline Petra & 4.7 & $\mathrm{~N}$ & $9.6^{*}$ & $\mathbf{S}$ & 6.7 & $\vec{M}$ \\
\hline Ronald & 4.5 & $\mathbf{N}$ & $8.8^{*}$ & $\mathrm{~N}$ & 11.1 & $\mathrm{~N}, \mathrm{C}$ \\
\hline Vlam & 2.6 & $\mathrm{~N}$ & $9.4^{*}$ & $\mathrm{~N}$ & 7.8 & $\mathrm{~N}$ \\
\hline Wageningen Rood & $9.5^{*}$ & $\mathbf{N}$ & 8.8 & $\mathrm{M}, \mathrm{C}$ & 9.3 & EC \\
\hline
\end{tabular}

ningen Rood) has a high shooting capacity at all BA concentrations. The third group (the remaining cultivars) shows an intermediate reaction, which for most of these cultivars is strongly dependent on the BA concentration. Cultivars of the second and the third group each appear to have their own optimum BA level; $5 \mathrm{mg} / 1 \mathrm{BA}$ is the optimum for Clementine and Ronald, $10 \mathrm{mg} / 1$ for Clara, Claudia, Jacqueline, Oranje Nassau and Wageningen Rood and $20 \mathrm{mg} / 1$ for Agnes, Geel Moor and Petra.

\section{Axillarybranching}

The influence of the kinetin concentration on axillary branching of shoots of 10 gerbera cultivars is shown in Table 2. The number of shoots after 7 weeks culture period appears to be determined by both the cultivar and the kinetin concentration. When considering the number of shoots produced, the cultivars can roughly be divided into 3 groups: (1) weak shooting (Clementine), (2) good shooting (Beatrix, Marleen, Nr. 20, Petra, Vlam and Wageningen Rood), and (3) extremely good shooting (Olga, Pari and Ronald) cultivars, all judged at their optimum kinetin concentration. When the cytokinin requirement to reach optimum shooting is considered, 3 groups of cultivars can be distinguished: with an optimum reaction at $1 \mathrm{mg} / \mathrm{l}$ kinetin (Wageningen Rood), $5 \mathrm{mg} / 1$ (Clementine, Pari, Petra and Vlam) or $10 \mathrm{mg} / \mathrm{l}$ (Beatrix, Olga, Marleen, Nr. 20 and Ronald).

The picture obtained by judging only the number of shoots is onesided, however. The quality of the shoots should also be taken into consideration. Leaf weight is considered as a satisfactory parameter. In Table 2 each cultivar received an asterisk at the kinetin concentration which resulted in the highest leaf weight per shoot. It is quite clear that in 5 cultivars (Beatrix, Olga, Nr. 20, Pari and Ronald) the kinetin concentration at which the optimum shoot weight is reached does not coincide with the optimum kinetin concentration for axillary 


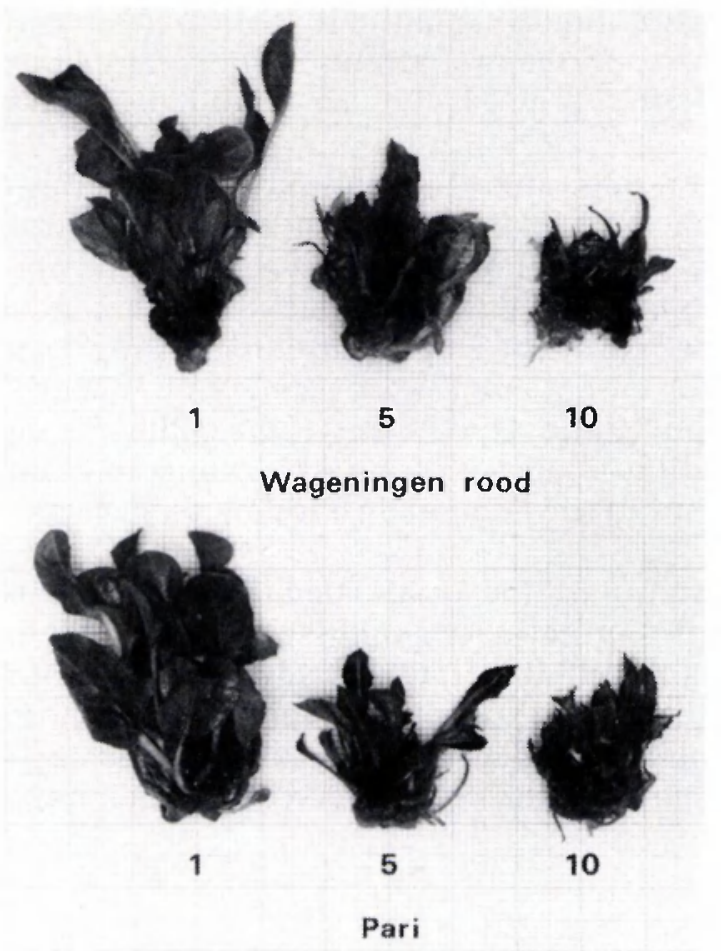

Fig. 1. Effect of the kinetin concentration $(1,5$ or $10 \mathrm{mg} / \mathrm{l})$ on axillary branching in excised shoots of two Gerbera cultivars. In both cultivars callus formation and leaf deformation occurred at 5 and $10 \mathrm{mg} / 1$ kinetin.

branching. Other quality characteristics are the absence of leaf deformations and the absence of callus formation at the bases of the shoots. When under the influence of certain kinetin concentrations many leaf deformations (see Table 2: $\mathrm{M}$ and $\mathrm{E}$ ) occur or when strong callus formation is induced (see Table 2: $\mathrm{C}$ ) shoot multiplication on these media should be avoided. This is illustrated in Fig. 1 for the cultivars Pari and Wageningen Rood.

\section{Conclusions and discussion}

From the foregoing it is clear that shoot formation on excised capitulum explants and axillary branching in excised shoots are both determined by cultivar and by cytokinin concentration in the medium. A comparison of the cultivars occurring both in Tables 1 and 2 is very difficult because 2 different cytokinins were used; in spite of this the conclusion seems justified that there is no clear correlation between the cytokinin requirement in the capitulum system and in the axillary shoot system. This is rather remarkable because in both systems dormant buds have to be activated by cytokinin. It is supposed that the shoot primordia in capitulum explants are in a quiescent state, which is much deeper than in the axillary buds in the axils of the leaves of a shoot; an indication for this hypothesis is that the percentages of shooting in Table 1 are low. Another 


\section{R. L. M. PIERIK ET AL.}

possibility is that the shoots on the capitulum explants are (partly) of adventitious origin; in that case a comparison of the two systems is not permitted because cytokinin requirement for the release of apical dominance is not the same as for adventitious bud formation.

The pratical consequences of our results can be summarized as follows. When the capitulum method is applied and the cytokinin requirement of a certain cultivar is not known, a concentration of $10 \mathrm{mg} / 1 \mathrm{BA}$ is the best advice, since 9 out of 15 cultivars (Table 1 ) reacted optimally at this concentration; an alternative advice is to cultivate one third of the explants at $5 \mathrm{mg} / 1$, one third at $10 \mathrm{mg} / 1$ and one third at $20 \mathrm{mg} / 1 \mathrm{BA}$ to determine the optimum BA concentration. When axillary shooting is needed, and the cytokinin requirement of the cultivar is unknown, the best advice is to choose a medium with $5 \mathrm{mg} / \mathrm{l} \mathrm{kinetin}$; at that concentration 7 out of totally 10 cultivars reacted optimally during prolonged subculture (see asterisks in Table 2).

An important practical conclusion from Table 2 is also that relatively high cytokinin levels can induce leaf deformation and strong callus formation in certain cultivars. The formation of callus and the regeneration of adventitious sprouts from this callus should be avoided, because it is a potential source of mutations. Another argument not to use too high cytokinin levels for axillary branching is that it leads to plants with a strong branching habit, as observed after their transfer to soil.

\section{References}

Hedtrich, C. M., 1979. Sprossregeneration aus Blättern und Vermehrung von Gerbera jamesonii. Gartenbauwissenschaft 44: 1-3.

Murashige, T., M. Serpa \& J. B. Jones, 1974. Clonal propagation of Gerbera through tissue culture. Hort Science 9: 175-180.

Pierik, R. L. M., \& Th. A. Segers, 1973. In vitro culture of midrib explants of Gerbera: adventitious root formation and callus induction. Z. Pflanzenphysiol. 69: 204-212.

Pierik, R. L. M., H. H. M. Steegmans \& J. J. Marelis, 1973. Gerbera plantlets from in vitro cultivated capitulum explants. Scientia Hort. 1: 117-119.

Pierik, R. L. M., J. L. M. Jansen, A. Maasdam \& M. Binnendijk, 1975. Optimalization of Gerbera plantlet production from excised capitulum explants. Scientia Hort. 3: 351-357. 